\title{
Is oxygen therapy beneficial for normoxemic patients with acute heart failure? A propensity score matched study
}

\section{Yue Yu}

Changzheng Hospital

\section{Ren-qi Yao}

Chinese PLA General Hospital

\section{Yu-feng Zhang}

Changzheng Hospital

\section{Su-yu Wang}

Changzheng Hospital

\section{Wang Xi}

Changzheng Hospital

\section{Jun-nan Wang}

Changzheng Hospital

\section{Xiao-yi Huang}

Changhai Hospital

\section{Yong-ming Yao}

Chinese PLA General Hospital

Zhinong Wang ( $\nabla$ wangzn007@smmu.edu.cn )

the Second Affiliated Hospital of Naval Medical University https://orcid.org/0000-0001-6308-7949

\section{Research}

Keywords: Acute heart failure (AHF), Death, Hyperoxia, Mortality, Oxygen therapy

Posted Date: November 2nd, 2020

DOI: https://doi.org/10.21203/rs.3.rs-64431/v3

License: (c) (1) This work is licensed under a Creative Commons Attribution 4.0 International License. Read Full License

Version of Record: A version of this preprint was published at Military Medical Research on July 9th, 2021. See the published version at https://doi.org/10.1186/s40779-021-00330-7. 


\section{Abstract}

Background: The clinical efficiency of routine oxygen therapy is uncertain in patients with acute heart failure (AHF) who do not have hypoxemia. The aim of this study was to investigate the association between oxygen therapy and clinical outcomes in normoxemic patients hospitalized with AHF using realworld data.

Methods: Normoxemic patients diagnosed with AHF on ICU admission from the electronic ICU (eICU) Collaborative Research Database were included in the current study, in which the study population was divided into the oxygen therapy group and the ambient-air group. Propensity score matching (PSM) was applied to create a balanced covariate distribution between patients receiving supplemental oxygen and those exposed to ambient air. Linear regression and logistic regression models were performed to assess the associations between oxygen therapy and length of stay (LOS), and all-cause in-hospital as well as ICU mortality rates, respectively. A series of sensitivity and subgroup analyses were conducted to further validate the robustness of our findings.

Results: A total of 2,922 normoxemic patients with AHF were finally included in the analysis. Overall, $42.1 \%(1,230 / 2,922)$ patients were exposed to oxygen therapy, and $57.9 \%(1,692 / 2,922)$ patients did not receive oxygen therapy (defined as the ambient-air group). After PSM analysis, 1,122 pairs of patients were matched: each patient receiving oxygen therapy was matched with a patient without receiving supplemental oxygen. The multivariable logistic model showed that there was no significant interaction between the ambient air and oxygen group for all-cause in-hospital mortality (odds ratio [OR] 1.30; 95\% confidence interval [Cl] 0.92-1.82; $P \otimes 0.138$ ) or ICU mortality (OR 1.39; 95\% Cl 0.83-2.32; $P \otimes 0.206$ ) in the post-PSM cohorts. In addition, linear regression analysis revealed that oxygen therapy was associated with prolonged ICU LOS (OR 1.11; 95\% Cl 1.06-1.15; Pख0.001) and hospital LOS (OR 1.06; 95\% Cl 1.01$1.10 ; P \otimes 0.009)$ after PSM. Furthermore, the absence of an effect of supplemental oxygen on mortality was consistent in all subgroups.

Conclusions: Routine use of supplemental oxygen in AHF patients without hypoxemia was not found to reduce all-cause in-hospital mortality or ICU mortality.

\section{Background}

Acute heart failure (AHF) is a life-threatening medical condition requiring immediate treatment and leading to urgent hospitalization (1). Supplemental oxygen therapy is a routine treatment modality in the management of AHF patients $(2,3)$. The underlying rationale behind oxygen therapy for AHF patients is to relieve dyspnea, or improve oxygenation for the threatened myocardial tissue, thereby alleviating myocardial injury and improving cardiac function (4-6). However, above-normal arterial oxygen tension can cause systemic vasoconstriction (7), overproduction of reactive oxygen species (ROS) (8), and, consequently, worsening of heart failure (HF). Currently, most studies have focused solely on AHF patients with refractory and progressive hypoxemia, and oxygen therapy is recommended in patients with 


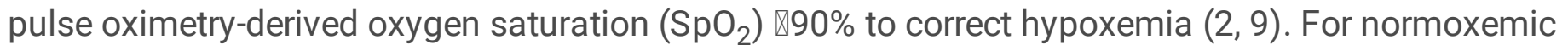
patients (defined as $\mathrm{SpO}_{2}$ between $90 \%$ and $100 \%$ ) presenting with $\mathrm{AHF}$, whether supplementary oxygen provides benefit or not remains highly uncertain.

This topic has been studied in other non-AHF clinical settings. For example, several randomized controlled trials (RCTs) have demonstrated that supplemental oxygen had no clinical benefits among patients without hypoxemia presenting with acute myocardial infarction (AMI) and others have suggested possible harm (10-15). Considering the contradictory findings regarding supplemental oxygen therapy, recent HF guidelines diverge from the previous consensus that oxygen should be administered routinely among AHF patients irrespective of oxygen saturation at baseline (16-18). However, this new direction is solely based on expert opinion or low-quality and nonrandomized clinical trials with a small sample size $(6,19,20)$. Given the cost of oxygen therapy and the ubiquitous use of oxygen among patients hospitalized with AHF, it is necessary to evaluate the correlation between supplemental oxygen and clinical outcomes $(4,21,22)$. Thus, this present study examined the hypothesis that routine use of supplemental oxygen in normoxemic AHF patients was not found to reduce all-cause in-hospital mortality or ICU mortality.

\section{Materials And Methods}

\section{Data sources and ethical statement}

The electronic Intensive Care Unit (eICU) Collaborative Research Database was a multi-center ICU database for more than 200,000 admissions from over 200 hospitals across the USA between 2014 and 2015 (23). The eICU database documents contained comprehensive charted events, including demographic data, diagnosis information via International Classification of Diseases, Ninth Revision (ICD-9) codes, vital sign measurements, laboratory findings and blood gas analyses, hourly physiologic readings from bedside monitors, various scoring systems, treatment information, and clinical outcomes. The establishment of the eICU database was approved by the Institutional Review Boards of the Massachusetts Institute of Technology (Cambridge, MA, USA). All the data were made anonymous prior to research analyses by the elCU programme, and hence the requirement for informed consent was waived. The study was complied with the ethical standards laid down in the 1964 Declaration of Helsinki and its later amendments. We finished the "Protecting Human Research Participants" curriculum, and obtained permission to access the dataset (authorization code: 33281932). In addition, we conducted this study in accordance with the STrengthening the Reporting of OBservational studies in Epidemiology (STROBE) statement (24).

\section{Population selection}

We included all ICU patients (aged $₫ 30$ years) with a primary diagnosis of AHF using ICD-9 diagnosis codes (ICD-9 codes: 404.91, 415.0, 428.0, 428.1, 428.21, 428.23, 428.31, 428.33, 428.41, and 428.43) from the elCU database. Patients were excluded who (1) had $\mathrm{SpO}_{2} \varangle 90 \%$ on admission; (2) presented with 
cardiac arrest or cardiogenic shock on admission; (3) were at risk of oxygen-induced hypercapnia (chronic obstructive pulmonary disease, asthma, or pneumonia) on admission; (4) stayed in the ICU for less than 24 hours; (5) required more intensive oxygen therapy including noninvasive ventilation (NIV) or invasive ventilation through endotracheal intubation during hospitalization; (6) received oxygen therapy at a flow rate of $10 \mathrm{~L} / \mathrm{min}$ or more $(10 \mathrm{~L} / \mathrm{min}$ is accepted as the maximum threshold value of flow rate for using face mask or nasal cannula); and (7) had incomplete or unobtainable documented information about oxygen saturation, oxygen therapy, and clinical outcomes.

\section{Data extraction and data processing}

The data were extracted from the database using structured query language (SQL) with PostgreSQL (version 9.6). The code that supported the elCU documentation and website was publicly available (https://github.com/mit-lcp/eicu-code). Demographic information included age, gender, and body mass index (BMI). BMI was calculated as weight $(\mathrm{kg})$ divided by height ${ }^{2}\left(\mathrm{~m}^{2}\right)$, using height and weight reported at the time of admission. Comorbidities on admission included sepsis, acute renal injury, and acute coronary syndrome. History of disease included atrial fibrillation, coronary artery disease (CAS), hypertension, stroke, diabetes mellitus, chronic kidney disease, and hyperthyroidism. Vital signs at presentation included systolic blood pressure, heart rate, and $\mathrm{SpO}_{2}$ on the first day. Laboratory findings and blood gas analysis data included albumin, creatinine, glucose, blood urea nitrogen, hematocrit, hemoglobin, blood platelets, white blood cells, potassium, and sodium. If vital signs were measured multiple times or patients received a laboratory test more than once during their hospitalization, an initial data on the first day after ICU admission was extracted for subsequent analyses. The severity of illness was assessed by three scoring systems (the Oxford Acute Severity of Illness Score [OASIS], the Sequential Organ Failure Assessment score [SOFA], and the Glasgow Coma Scale [GCS]). These scoring systems were calculated within the first 24 hours after admission using the values associated with the greatest severity of illness.

For treatment information, each admitted patient was treated independently, although some patients in the dataset might have had multiple admissions. Routine oxygen therapy in this study could refer to oxygen supplementation methods either via face mask or nasal cannula, because the elCU database did not provide detailed information to differentiate these two methods. Patients who received NIV or invasive ventilation during hospitalization were excluded. We took the average value of the $\mathrm{SpO}_{2}$ measurements during oxygen therapy as a measure of the central tendency of oxygen exposure. To address concerns about the time dependency of oxygen exposure, the duration of oxygen therapy was also recorded for subsequent analyses. Other treatment information included intra-aortic balloon pump, renal replacement treatment, and in-hospital medication administration (inotrope, diuretic, angiotensinconverting-enzyme inhibitors/angiotensin receptor blockers [ACEI/ARB], calcium channel blocker [CCB], and beta-blocker). Additionally, all the therapeutic methods (intra-aortic balloon pump, renal replacement treatment, and in-hospital medication) were implemented in all study participants prior to the initiation of oxygen therapy. 
As severe data missing might lead to bias, variables with over $20 \%$ missing values were not taken into subsequent analysis. Correspondingly, multiple imputation was used for processing variables with less than $20 \%$ missing values $(25,26)$.

\section{Endpoints}

The primary endpoint of our study was all-cause in-hospital mortality, which was defined as survival status at hospital discharge. We selected all-cause ICU mortality and ICU and hospital length of stay (LOS) as secondary endpoints. ICU and hospital LOS were calculated as the total duration spent in the ICU and hospital since hospital admission separately. Patients with missing survival outcome information were excluded from the final cohort.

\section{Statistical analysis}

Normoxemic patients with AHF were divided into the oxygen therapy group and the ambient-air group. Baseline characteristics of enrolled participants were presented and compared between two groups by using either Student $t$ test, Kruskal Wallis rank test, Pearson's $\chi^{2}$ test or Fisher's exact test as appropriated. Continuous variables were characterized as mean (standardized differences [SD]) or median (interquartile range [IQR]), while categorical or ranked data were shown as count and proportion.

Given the observational nature of the current study, propensity score matching (PSM) was used to minimize the effect of potential confounders. A logistic regression model was constructed to calculate and assign each patient a propensity score, which was defined as the likelihood of being exposed to an intervention. Next, 1:1 matching (the oxygen therapy group $v s$. the ambient-air group) without replacement was performed using a nearest neighbor matching algorithm, with a fixed caliper width of 0.05. The standardized mean difference (SMD) was calculated to evaluate the efficiency of PSM in reducing the differences between the two groups.

In the pre-PSM and post-PSM cohorts, logistic regression models were employed to investigate associations between oxygen therapy and clinical outcomes adjusting for confounding variables selected based on $P \otimes 0.05$ in the univariate analysis, in which the Akaike information criterion was applied as the selection criteria of the optimal model. Linear regression was used to assess the correlation of oxygen therapy with length of stay, and the odds ratios (ORs) were presented using the formula OR囚 $\mathrm{e}^{\beta i}$. A series of sensitivity and subgroup analyses were performed to further assess the association between oxygen therapy and all-cause in-hospital mortality, including duration of oxygen therapy, median $\mathrm{SpO}_{2}$ during hospitalization, age, De Nova AHF, history of atrial fibrillation, history of myocardial infarction, history of stroke, history of hypertension, history of chronic kidney disease, and renal replacement treatment.

A two-tailed $P$ value of less than 0.050 was considered to be statistical significance. All statistical analyses were performed using SPSS software (version 22.0; IBM Corporation, St. Louis, Missouri, USA) and R software (version.3.6.1; The R Project for Statistical Computing, TX, USA; http://www.r-project.org). 


\section{Results}

\section{Basic characteristics}

During the study period, 15,187 critically ill patients were admitted with AHF. Consequently, after excluding the patients according to the selection criteria, 2,922 eligible patients were enrolled in the current study (Figure 1). The patients included in the final cohort had a median age of 72 (61-82) years, $54.3 \%(1,586 / 2,922)$ patients were men, and $39.5 \%(1,155 / 2,922)$ patients were identified as having de novo AHF (Table 1$)$.

Table 1. Baseline characteristics of normoxemic patients with AHF between the two groups before matching 


\begin{tabular}{|c|c|c|c|c|c|}
\hline Characteristics & $\begin{array}{l}\text { Total } \\
(\mathrm{N}=2922)\end{array}$ & $\begin{array}{l}\text { Ambient Air } \\
(\mathrm{N}=1692)\end{array}$ & $\begin{array}{l}\text { Oxygen } \\
\text { Therapy } \\
(\mathrm{N}=1230)\end{array}$ & $P$ value & SMD \\
\hline \multicolumn{6}{|l|}{ Demographics } \\
\hline Age, years & $\begin{array}{l}72.0(61.0- \\
82.0)\end{array}$ & $\begin{array}{l}72.0(61.0- \\
82.0)\end{array}$ & $\begin{array}{l}72.0(60.0- \\
82.0)\end{array}$ & 0.316 & 0.047 \\
\hline Gender, male & $\begin{array}{l}1586 \\
(54.3 \%)\end{array}$ & $915(54.1 \%)$ & $671(54.6 \%)$ & 0.799 & 0.010 \\
\hline BMI, $\mathrm{kg} / \mathrm{m}^{2}$ & $\begin{array}{l}28.7(24.2- \\
34.5)\end{array}$ & $\begin{array}{l}28.6(24.3- \\
34.4)\end{array}$ & $\begin{array}{l}28.8(24.2- \\
34.7)\end{array}$ & 0.716 & 0.004 \\
\hline de novo $\mathrm{AHF}$ & $\begin{array}{l}1155 \\
(39.5 \%)\end{array}$ & $659(38.9 \%)$ & $496(40.3 \%)$ & 0.452 & 0.028 \\
\hline \multicolumn{6}{|c|}{ Comorbidities on admission } \\
\hline Sepsis & $306(10.5 \%)$ & $183(10.8 \%)$ & $123(10.0 \%)$ & 0.477 & 0.027 \\
\hline AKI & $65(2.2 \%)$ & $45(2.7 \%)$ & $20(1.6 \%)$ & 0.061 & 0.071 \\
\hline \multicolumn{6}{|l|}{ History of disease } \\
\hline $\mathrm{AF}$ & $668(22.9 \%)$ & 381 (22.5\%) & $287(23.3 \%)$ & 0.604 & 0.019 \\
\hline \multicolumn{6}{|l|}{ CAD } \\
\hline MI & $561(19.2 \%)$ & $331(19.6 \%)$ & $230(18.7 \%)$ & 0.559 & 0.022 \\
\hline PCI & $335(11.5 \%)$ & $200(11.8 \%)$ & $135(11.0 \%)$ & 0.479 & 0.027 \\
\hline CABG & $344(11.8 \%)$ & $194(11.5 \%)$ & $150(12.2 \%)$ & 0.546 & 0.023 \\
\hline Hypertension & $\begin{array}{l}1869 \\
(64.0 \%)\end{array}$ & $\begin{array}{l}1041 \\
(61.5 \%)\end{array}$ & $828(67.3 \%)$ & 0.001 & 0.121 \\
\hline Stroke & $301(10.3 \%)$ & $178(10.5 \%)$ & $123(10.0 \%)$ & 0.648 & 0.017 \\
\hline $\mathrm{DM}$ & $\begin{array}{l}1145 \\
(39.2 \%)\end{array}$ & $656(38.8 \%)$ & 489 (39.8\%) & 0.590 & 0.020 \\
\hline CKD & $775(26.5 \%)$ & $451(26.7 \%)$ & $324(26.3 \%)$ & 0.850 & 0.007 \\
\hline Hyperthyroidism & $346(11.8 \%)$ & $190(11.2 \%)$ & $156(12.7 \%)$ & 0.230 & 0.045 \\
\hline \multicolumn{6}{|c|}{ Vital signs at presentation } \\
\hline $\mathrm{SBP}, \mathrm{mmHg}$ & $\begin{array}{l}121.0 \\
(120.0- \\
127.0)\end{array}$ & $\begin{array}{l}121.0 \\
(120.0- \\
127.0)\end{array}$ & $\begin{array}{l}121.0 \\
127.0)\end{array}$ & 0.467 & 0.021 \\
\hline $\mathrm{HR}$, beats/min & $\begin{array}{l}86.0(73.0- \\
101.0)\end{array}$ & $\begin{array}{l}86.0(73.0- \\
101.0)\end{array}$ & $\begin{array}{l}87.0(74.0- \\
101.0)\end{array}$ & 0.179 & 0.043 \\
\hline $\mathrm{SpO}_{2}, \%$ & $\begin{array}{l}97.0(95.0- \\
99.0)\end{array}$ & $\begin{array}{l}97.0(95.0- \\
99.0)\end{array}$ & $\begin{array}{l}97.0(95.0- \\
99.0)\end{array}$ & 0.946 & 0.013 \\
\hline \multicolumn{6}{|c|}{$\begin{array}{l}\text { Laboratory findings and } \\
\text { blood gas analysis }\end{array}$} \\
\hline Albumin, mg/dL & $3.1(2.7-3.5)$ & $3.1(2.7-3.5)$ & $3.1(2.7-3.5)$ & 0.941 & 0.007 \\
\hline Creatinine, $\mu \mathrm{mol} / \mathrm{L}$ & $1.3(0.9-2.2)$ & $\begin{array}{l}1.310(0.9- \\
2.2)\end{array}$ & $1.3(0.9-2.1)$ & 0.195 & 0.062 \\
\hline Glucose, mg/dL & $\begin{array}{l}109.0 \\
138.0)\end{array}(91.0-$ & $\begin{array}{l}109.0(91.0- \\
137.3)\end{array}$ & $\begin{array}{l}110.0(91.0- \\
139.0)\end{array}$ & 0.420 & 0.010 \\
\hline
\end{tabular}




\begin{tabular}{|c|c|c|c|c|c|}
\hline $\mathrm{BUN}, \mathrm{mg} / \mathrm{dL}$ & $\begin{array}{l}27.0(18.0- \\
44.0)\end{array}$ & $\begin{array}{l}27.0(18.0- \\
44.0)\end{array}$ & $\begin{array}{l}27.0(18.0- \\
43.0)\end{array}$ & 0.957 & 0.038 \\
\hline Hematocrit, \% & $32.1(6.9)$ & $31.9(6.9)$ & $32.3(6.9)$ & 0.110 & 0.060 \\
\hline Hemoglobin, g/dL & $\begin{array}{l}10.5(8.8- \\
12.1)^{(-8}\end{array}$ & $\begin{array}{l}10.5(8.8- \\
12.0)\end{array}$ & $\begin{array}{l}10.5(8.9- \\
12.2)\end{array}$ & 0.137 & 0.062 \\
\hline Platelet, $10^{9} / \mathrm{L}$ & $\begin{array}{l}183.5 \\
(136.0- \\
241.0)\end{array}$ & $\begin{array}{l}180.0 \\
(134.0- \\
238.0)\end{array}$ & $\begin{array}{l}186.8(138.0- \\
244.0)\end{array}$ & 0.072 & 0.101 \\
\hline WBC, $10^{9} / \mathrm{L}$ & $\begin{array}{l}8.5(6.3- \\
11.6)\end{array}$ & $\begin{array}{l}8.4(6.3- \\
11.4)\end{array}$ & $\begin{array}{l}8.6(6.4- \\
11.8)\end{array}$ & 0.224 & 0.011 \\
\hline Potassium, $\mathrm{mmol} / \mathrm{L}$ & $3.9(3.5-4.3)$ & $3.9(3.5-4.3)$ & $3.9(3.5-4.3)$ & 0.784 & 0.018 \\
\hline Sodium, mmol/L & $\begin{array}{l}136.0 \\
(133.0- \\
139.0)\end{array}$ & $\begin{array}{l}137.0 \\
(134.0- \\
140.0)\end{array}$ & $\begin{array}{l}135.0(132.0- \\
138.0)\end{array}$ & 0.002 & 0.125 \\
\hline \multicolumn{6}{|l|}{ Scoring system } \\
\hline OASIS & $\begin{array}{l}19.0(14.0- \\
25.0)\end{array}$ & $\begin{array}{l}20.0(15.0- \\
26.0)\end{array}$ & $\begin{array}{l}19.0(12.0- \\
25.0)\end{array}$ & $<0.001$ & 0.214 \\
\hline SOFA & $4.0(2.0-6.0)$ & $4.0(2.0-6.0)$ & $4.0(2.0-6.0)$ & 0.248 & 0.053 \\
\hline GCS & $\begin{array}{l}15.0(15.0- \\
15.0)\end{array}$ & $\begin{array}{l}15.0(15.0- \\
15.0)\end{array}$ & $\begin{array}{l}15.0(15.0- \\
15.0)\end{array}$ & 0.665 & 0.008 \\
\hline \multicolumn{6}{|l|}{ Management of AHF } \\
\hline Intra-aortic balloon pump & $41(1.4 \%)$ & $23(1.4 \%)$ & $18(1.5 \%)$ & 0.813 & 0.009 \\
\hline RRT & $149(5.1 \%)$ & $102(6.0 \%)$ & 47 (3.8\%) & 0.007 & 0.102 \\
\hline \multicolumn{6}{|l|}{ In-hospital medication } \\
\hline Inotrope & $173(15.9 \%)$ & $73(14.3 \%)$ & $100(18.1 \%)$ & 0.001 & 0.158 \\
\hline Diuretic & $\begin{array}{l}2221 \\
(76.0 \%)\end{array}$ & $\begin{array}{l}1259 \\
(74.4 \%)\end{array}$ & $962(78.2 \%)$ & $<0.001$ & 0.150 \\
\hline ACEI/ARB & $\begin{array}{l}1730 \\
(59.2 \%)\end{array}$ & 958 (56.6\%) & 772 (62.8\%) & $<0.001$ & 0.214 \\
\hline ССВ & $171(5.9 \%)$ & $82(4.8 \%)$ & $89(7.2 \%)$ & 0.007 & 0.100 \\
\hline Beta-blocker & $695(23.8 \%)$ & $290(47.1 \%)$ & $405(62.9 \%)$ & $<0.001$ & 0.371 \\
\hline \multicolumn{6}{|l|}{ Oxygen therapy } \\
\hline $\begin{array}{l}\text { Duration of oxygen therapy, } \\
\text { days }\end{array}$ & l & I & $2.5(1.6-4.1)$ & 1 & l \\
\hline $\begin{array}{l}\text { Median } \mathrm{SpO}_{2} \text { during } \\
\text { treatment period, \% }\end{array}$ & $\begin{array}{l}97.9(96.5- \\
98.8)\end{array}$ & $\begin{array}{l}97.1(95.5- \\
97.8)\end{array}$ & $\begin{array}{l}98.7(97.4- \\
99.8)\end{array}$ & $<0.001$ & l \\
\hline
\end{tabular}

Note: Values are $\mathrm{n}(\%)$, mean $\pm \mathrm{SD}$, or median (interquartile range).

Abbreviations: SMD: Standardized mean difference; BMI: Body mass index; AHF: Acute heart failure; AKI: Acute kidney injury; AF: Atrial fibrillation; CAD: Coronary artery disease; MI: Myocardial infarction; PCI: Percutaneous coronary intervention; CABG: Coronary artery bypass grafting; DM: Diabetes mellitus; CKD: Chronic kidney disease; SBP: Systolic blood pressure; HR: heart rate; $\mathrm{SpO}_{2}$ : Pulse oximetry-derived oxygen saturation; BUN: Blood urea nitrogen; 
WBC: White blood cell; OASIS: Oxford Acute Severity of Illness Score; SOFA: Sequential Organ Failure Assessment Score; GCS: Glasgow Coma Scale; RRT: Renal replacement treatment; ACEI/ARB: Angiotensin-converting-enzyme inhibitors/angiotensin receptor blockers; CCB: Calcium channel blocker.

Overall, $42.1 \%(1,230 / 2,922)$ patients were exposed to oxygen therapy, and $57.9 \%(1,692 / 2,922)$ patients did not receive oxygen therapy (defined as the ambient-air group). The median duration of oxygen therapy was 2.5 (1.6-4.1) days. The comparison of baseline characteristics between these two groups was summarized in Table 1. There were significant differences in history of disease (hypertension: 61.5\% [1,041/1,692] vs. 67.3\% [828/1,230]; P凶0.001) and scoring systems (OASIS: 20.0 [15.0-26.0] vs. 19.0 [12.025.0]; $P \otimes 0.001$ ) between the oxygen therapy group and the ambient-air group. Additionally, patients exposed to oxygen therapy were more likely to receive medication administration during hospitalization (inotropes: 4.3\% [73/1,692] vs. 8.1\% [100/1,230]; P冈0.001; diuretic: 4.4\% [75/1,692] vs. 8.0\% [99/1,230]; $P]$ 0.001; ACEI/ARB: 6.6\% [111/1,692] vs. 12.8\% [158/1,230]; P凶0.001; CCB: 4.8\% [82/1,692] vs. 7.2\% [89/1,230]; Pख0.007; and beta-blocker: 17.1\% [290/1,692] vs. 32.9\% [405/1,230]; $P \otimes 0.001)$. No difference was observed in admission $\mathrm{SpO}_{2}$ level (97.0\% [95.0\%-99.0\%] vs. 97.0\% [95.0\%-99.0\%]; $\left.P \bowtie 0.946\right)$ between these two groups. Furthermore, during the intervention, mean $\mathrm{SpO}_{2}$ level of the oxygen therapy group was higher than that of the ambient-air group (98.7\% [97.4\%-99.8\%] vs. 97.1\% [95.5\%-97.8\%]; P凶0.001).

\section{Relationship between oxygen therapy and outcomes}

Univariable and multivariable logistic regression models were employed to examine the difference in allcause in-hospital and ICU mortality rates between these two groups. In the pre-matched cohort, $6.2 \%$ $(104 / 1,692)$ patients in the ambient-air arm and $8.0 \%(98 / 1,230)$ patients in the oxygen therapy arm died in the hospital (OR 1.32; 95\% confidence interval [Cl] 0.99-1.76; P凶0.056) (Table 2; Table S1). 3.5\% $(43 / 1,230)$ patients in the oxygen group died in the ICU in comparison to $2.5 \%(42 / 1,692)$ patients in the ambient-air group (OR 1.42; 95\% Cl 0.92-2.19; P凶0.109) (Table 2; Table S2). By the multivariable analysis, no differences were observed for in-hospital mortality (OR 1.34; 95\% Cl 0.98-1.84; P凶0.067) (Table 2; Table S1) or ICU mortality (OR 1.58; $95 \% \mathrm{Cl} 0.97-2.56 ; P \otimes 0.066)$ after adjusting for possible confounding factors associated with mortality (Table 2; Table S1; Table S2). Moreover, linear regression was used to evaluate the association between oxygen therapy and ICU as well as hospital LOS. Nevertheless, oxygen therapy was significantly associated with prolonged ICU LOS (OR 1.15; 95\% Cl 1.11-1.19; $P \otimes 0.001$ ) and hospital LOS (OR 1.07; 95\% Cl 1.04-1.11; P冈0.001) (Table 2).

Table 2. Association between oxygen therapy and clinical outcomes in normoxemic patients with AHF 


\begin{tabular}{|lllll|}
\hline Clinical outcomes & Ambient Air & Oxygen Therapy & OR (95\% CI) & $P$ value \\
\hline Pre-matched cohort & $\mathrm{N}=1692$ & $\mathrm{~N}=1230$ & & \\
\hline All-cause in-hospital mortality & & & & \\
\hline Univariable logistic model & $104(6.1 \%)$ & $98(8.0 \%)$ & $1.32(0.99,1.76)$ & 0.056 \\
\hline Multivariable logistic model & $104(6.1 \%)$ & $98(8.0 \%)$ & $1.34(0.98,1.84)$ & 0.067 \\
\hline All-cause ICU mortality & & & & \\
\hline Univariable logistic model & $42(2.5 \%)$ & $43(3.5 \%)$ & $1.42(0.92,2.19)$ & 0.109 \\
\hline Multivariable logistic model & $42(2.5 \%)$ & $43(3.5 \%)$ & $1.58(0.97,2.56)$ & 0.066 \\
\hline Length of ICU stay, days & $2.2(1.5-3.5)$ & $2.7(1.8-4.6)$ & $1.15(1.11,1.19)$ & $<0.001$ \\
\hline Length of hospital stay, days & $6.5(4.0-11.3)$ & $7.8(4.8-13.1)$ & $1.07(1.04,1.11)$ & $<0.001$ \\
\hline & & & & \\
\hline Post-matched cohort & $\mathrm{N}=1122$ & $\mathrm{~N}=1122$ & & \\
\hline All-cause in-hospital mortality & & & & \\
\hline Univariable logistic model & $74(6.6 \%)$ & $89(7.9 \%)$ & $1.22(0.89,1.68)$ & 0.223 \\
\hline Multivariable logistic model & $74(6.6 \%)$ & $89(7.9 \%)$ & $1.30(0.92,1.82)$ & 0.138 \\
\hline All-cause ICU mortality & & & & \\
\hline Univariable logistic model & $34(3.0 \%)$ & $40(3.6 \%)$ & $1.18(0.74,1.88)$ & 0.479 \\
\hline Multivariable logistic model & $34(3.0 \%)$ & $40(3.6 \%)$ & $1.39(0.83,2.32)$ & 0.206 \\
\hline Length of ICU stay, days & $2.2(1.5-3.8)$ & $2.7(1.7-4.4)$ & $1.11(1.06,1.15)$ & $<0.001$ \\
\hline Length of hospital stay, days & $6.8(4.1-11.2)$ & $7.6(4.6-12.9)$ & $1.06(1.01,1.10)$ & 0.009 \\
\hline
\end{tabular}

Abbreviations: AHF: Acute heart failure; ICU: Intensive care unit; OR: Odds ratio; CI: Confidence interval.

By the PSM analysis, 2,244 patients remained in the post-PSM cohort, and 1,122 patients who received oxygen therapy were matched with 1,122 patients who did not receive oxygen. All the variables listed in Table 1 (except for duration of oxygen therapy and mean $\mathrm{SpO}_{2}$ during treatment period) were considered in the PSM analysis. The characteristics of matched patients were compared, and the SMDs for all the individual covariates were provided. Differences in all variables between the oxygen therapy group and the ambient-air group were reduced and had no statistical significances measured by SMDs that were less than $10 \%$ for all variables (Table 1 ; Table S3).

Similar to the results in the pre-matched model, the logistic model showed that there was no significant interaction between the ambient air and oxygen groups with regard to all-cause in-hospital mortality (univariable analysis: OR 1.22; $95 \% \mathrm{Cl} 0.89-1.68 ; P \otimes 0.223$; multivariable analysis: OR $1.30 ; 95 \% \mathrm{Cl} 0.92-$ 1.82; $P \otimes 0.138$ ) (Table 2; Table S4) and ICU mortality (univariable analysis: OR 1.18; $95 \% \mathrm{Cl} 0.74-1.88 ; P]$ 0.479; multivariable analysis: OR 1.39; $95 \% \mathrm{Cl} 0.83-2.32, P \otimes 0.206)$ (Table 2; Table S5). Likewise, the results of linear regression analysis revealed that oxygen therapy was associated with prolonged ICU LOS (OR 1.11; 95\% Cl 1.06-1.15; Pख0.009) and hospital LOS (OR 1.06; 95\% Cl 1.01-1.10; Pख0.009) (Table 2). 


\section{Sensitivity analysis}

A series of sensitivity analyses were performed to validate the robustness of our findings (Figure 2). When taking the $\mathrm{SpO}_{2}$ target of oxygen therapy into consideration, we noticed that patients with a highnormal range of $95 \% \varangle \mathrm{SpO}_{2} \leq 100 \%$ were associated with an increased risk of in-hospital mortality when compared with the ambient-air group (OR 1.44; $95 \% \mathrm{Cl} 1.03-2.03, P \otimes 0.034)$. Oxygen therapy was also associated with deteriorative in-hospital mortality in AHF patients receiving oxygen therapy for $\$ 6$ days (OR 3.34; 95\% Cl 2.15-5.20; $P \otimes 0.001$ ), the etiology of AMI (OR 2.95; 95\% Cl 1.09-7.99; $P \otimes 0.033$ ), and the history of atrial fibrillation (OR 1.69; $95 \% \mathrm{Cl} 1.00-2.87 ; P \otimes 0.049)$. Other subgroups were not found to be significant.

\section{Discussion}

This study demonstrated that routine oxygen therapy was not found to reduce the composite endpoints of all-cause in-hospital and ICU mortality rates in normoxemic patients with AHF. The results also suggested that oxygen therapy might be closely correlated to increased LOS in ICU and hospital. Since the competitive risks existed in the secondary endpoints of ICU and hospital LOS, the significant correlation of oxygen supplementation with prolonged ICU ad hospital LOS should be interpreted cautiously. In addition, the absence of an effect of supplemental oxygen on mortality was consistent in all subgroups. To our knowledge, this study was the first to investigate the association between supplemental oxygen and short-term clinical outcomes based on a multi-center and critical care cohort of AHF patients without hypoxia.

Oxygen therapy remains a cornerstone for the treatment of AHF, while guidelines provide various recommendations on its appropriate use, reflecting the lack of robust evidence on such "cornerstone" therapy. The Canadian Cardiovascular Society (CCS) HF guidelines have recommended that supplemental oxygen should be considered for patients who are hypoxemic, and should be used cautiously in normoxemic patients due to concerns of increasing systemic vascular resistance and reducing cardiac output (27). The latest European Society of Cardiology (ESC) and the Taiwan Society of Cardiology (TSOC) guidelines have indicated that oxygen should not be used routinely for AHF patients without hypoxemia $(2,28)$. Recommendations on oxygen therapy in normoxemic patients with AHF are not mentioned in the latest American College of Cardiology (ACC)/American Heart Association (AHA)/Heart Failure Society of America (HFSA) (1), or the National Institute for Health and Care Excellence (NICE) guidelines (16). However, most of these recommendations appear to be solely based on expert opinion rather than high-quality evidence, and we hope our findings might provide certain evidence for this point of view. In addition, one observational study documented supplemental oxygen to be prescribed among at least half of AHF patients in the emergency department (ED), regardless of $\mathrm{SpO}_{2}$ level (4). A lack of clinical benefit could mean that by departing from this practice, it might be significant not only for patients to have a lower treatment burden but also to have reduced medical expenses. 
Our findings were consistent with the results of studies that evaluated the impacts of supplemental oxygen therapy in other clinical settings. Several RCTs and meta-analyses have demonstrated that oxygen therapy does not significantly reduce all-cause mortality, and can even increase the incidence of early myocardial injury and infarct size among AMI patients with normoxemia $(8,10-13,29-33)$. A total of eleven RCTs including 6,366 patients with acute stroke showed a nonsignificant increase in mortality at three, six, and twelve months in patients who received normobaric oxygen compared with those who received ambient air (34). In addition, it was standard to perform neonatal resuscitation with $100 \%$ oxygen until multiple RCTs demonstrated that room air resulted in a lower incidence of infant mortality and hypoxic ischemic encephalopathy than $100 \%$ oxygen, thereby contributing to a dramatic change in guidelines and practice (35).

Although hypoxic patients can benefit from supplemental oxygen to correct hypoxia, supplementation above normoxia seems to be futile as the hemodynamic response to hyperoxia outbalances the benefit of additionally dissolved oxygen in the blood. The cardiovascular effects of hyperoxia are mainly mediated by following pathways: endothelial production of ROS (36) and hyperoxia-induced vasoconstriction in the coronary (37), retinal (38), and cerebral vascular bed (39). The excessive formation of ROS outweighs the antioxidant capacities of the cells, and results in oxidative stress and a cascade of adverse outcomes including damage to nucleic acids, proteins and lipids, and activation of apoptotic as well as necrotic pathways causing cell death $(6,40,41)$. Furthermore, ROS-induced closure of adenosine triphosphate (ATP)-dependent potassium channels and activation of ligand-gated calcium channels in vascular smooth muscle cells lead to the peripheral vasoconstriction and decreased regional blood flow in most vascular beds $(42,43)$. Ruggiu et al. (44) demonstrated that hyperoxia at any time of the ICU stay significantly decreases OS and is an independent mortality risk factor regardless of the cause of patient admission. A study showed that extreme hyperoxia $\left(\mathrm{FiO}_{2} \otimes 1.0\right.$; arterial partial pressure of oxygen $\left[\mathrm{PaO}_{2}\right] \rrbracket$ $300 \mathrm{mmHg}$ ) was associated with an $8 \%$ to $30 \%$ decrease in coronary blood flow, impairment of cardiac relaxation and contractility, and increased left ventricular filling pressures in patients with congestive HF (45). In addition, two studies revealed that hyperoxia caused peripheral vasoconstriction, increased systemic vascular resistance, and did not increase systemic oxygen delivery in HF patients $(19,46)$. Haque et al. found an increase in pulmonary capillary wedge pressure caused by hyperoxia in AHF patients with this effect starting at an $\mathrm{FiO}_{2}$ level of 0.24 (47). However, Nael et al (48) conducted a study to evaluate the impact of early hyperoxia exposure among AHF patients admitted with pulmonary congestion and treated with oxygen therapy, and did not find any difference in 30-day mortality between patients with phases of hyperoxia and without hyperoxia. Therefore, a multicenter, prospective, RCT is needed to further assess the association between hyperoxia and mortality in AHF patients, and provide a definitive answer about the consequences.

The goal of oxygen therapy remains uncertain for AHF patients. In our subgroup analysis, we divided patients by mean $\mathrm{SpO}_{2}$ level during hospitalization into a low-normal $\left(90 \% \leq \mathrm{SpO}_{2} \leq 95 \%\right)$ and a highnormal $\left(95 \% \bigotimes \mathrm{SpO}_{2} \leq 100 \%\right)$ cohort. Among patients with a high-normal range of $95 \% \otimes \mathrm{SpO}_{2} \leq 100 \%$, oxygen therapy was associated with worse clinical outcomes compared to the ambient-air group. 
Although measurement of $\mathrm{SpO}_{2}$ might be inappropriate tool to quantify the magnitude of hyperoxemia, some researchers reported that the prevalence of arterial hyperoxia increased when $\mathrm{SpO}_{2}$ was $₫ 95 \%$ in a cross-sectional study of one hundred mechanically ventilated patients admitted to the ICU (49). Improving Oxygen Therapy in Acute-illness (IOTA) systematic review and meta-analysis concluded that liberal oxygen therapy (without setting an upper limit of $\mathrm{SpO}_{2}$ ) could increase mortality, and $\mathrm{SpO}_{2}$ should not exceed $96 \%$ among acutely ill adults (50). Additionally, the Thoracic Society of Australia and New Zealand (TSANZ) and the British Thoracic Society (BTS) have recommend that oxygen is stopped above an upper limit of $\mathrm{SpO}_{2}$ in critically ill patients (TSANZ: $96 \%$; BTS: $\left.98 \%\right)(51,52)$. However, a recent study investigated the effect of oxygen titrated to high $\left(\mathrm{SpO}_{2} \geq 96 \%\right)$ vs. low $\left(90 \% \leq \mathrm{SpO}_{2} \leq 92 \%\right)$ pulse oximetry targets in fifty patients hospitalized with AHF, and implicated that the difference of baseline and 72 hours $\mathrm{N}$-terminal pro-brain-type natriuretic peptide (NT-proBNP) levels were of no obvious significance between groups with high and low $\mathrm{SpO}_{2}$ targets (53). Nonetheless, limited by the small sample size and few death events, they did not assess the impact of these two groups on clinical endpoints (such as in-hospital mortality).

Notablely, the current study must be interpreted in the context of several limitations. First, all patients with an admission $\mathrm{SpO}_{2}$ level $\geq 90$ \%were included in our study cohort, yet misclassification could not be ruled out, as $\mathrm{SpO}_{2}$ was measured by local procedures and therefore subjected to selection bias. Second, to avoid including patients developing refractory and progressive hypoxemia during intervention, we excluded patients receiving more intensive oxygen therapy including endotracheal intubation and NIV during hospitalization. However, this might lead to selection biases, and these patients receiving more advanced oxygen support should be considered separately in the further study. Third, the elCU database did not provide any information before patients' admission, therefore we could not identify whether patients enrolled in this study received oxygen therapy prior to admission. Fourth, we did not include detailed information with regard to oxygen therapy (oxygen flow rate and oxygen concentration), or some important laboratory variables (such as NT-proBNP) due to more than $20 \%$ missing values, which might be related to the efficacy of oxygen therapy. Another limitation was the retrospective nature of the study. Retrospective studies almost always have bias because prognostic factors are unequally distributed between patients exposed or not exposed to an intervention. Although multivariate logistic regression and PSM analysis were applied in the present study to control the covariate imbalance and selection bias, more high-quality clinical trials are needed to strengthen our results.

\section{Conclusion}

Routine use of supplemental oxygen in normoxemic patients with AHF was not found to reduce the composite of all-cause in-hospital or ICU mortality. Thus, our results provided supporting evidence for the rationale use of oxygen therapy in the current guidelines.

\section{Abbreviations}


AHF: Acute heart failure; ROS: Reactive oxygen species; HF: Heart failure; $\mathrm{SpO}_{2}$ : Pulse oximetry-derived oxygen saturation; RCT: Randomized controlled trial; AMI: Acute myocardial infarction; elCU: Electronic Intensive Care Unit; ICD-9: International Classification of Diseases, Ninth Revision; STROBE:

STrengthening the Reporting of OBservational studies in Epidemiology; NIV: Noninvasive ventilation; SQL: Structured query language; BMI: Body mass index; OASIS: Oxford Acute Severity of Illness Score; SOFA: Sequential Organ Failure Assessment; GCS: Glasgow Coma Scale; ACEI/ARB: Angiotensin-convertingenzyme inhibitors/angiotensin receptor blockers; CCB: Calcium channel blocker; LOS: Length of stay; SD: Standardized difference; IQR: Interquartile range; PSM: Propensity score matching; SMD: Standardized mean difference; OR: Odds ratio; Cl: Confidence interval; CCS: Canadian Cardiovascular Society; ESC: European Society of Cardiology; TSOC: Taiwan Society of Cardiology; ACC: American College of Cardiology; AHA: American Heart Association; HFSA: Heart Failure Society of America; NICE: National Institute for Health and Care Excellence; ED: Emergency department; ATP: Adenosine triphosphate; $\mathrm{FiO}_{2}$ : Fraction of inspired oxygen; $\mathrm{PaO}_{2}$ : Arterial partial pressure of oxygen; IOTA: Improving Oxygen Therapy in Acute-illness; TSANZ: Thoracic Society of Australia and New Zealand; BTS: British Thoracic Society; NTproBNP: N-terminal pro-brain-type natriuretic peptide.

\section{Declarations}

\section{Acknowledgements}

Not applicable.

\section{Authors' contributions}

YY and RQY designed the study, collected and analyzed data, and drafted the manuscript; YFZ and SYW helped in the statistical analysis and result interpretation; WX, JNW, and XYH prepared the figures and interpret the results; YMY and ZNW were identified as the guarantor of the paper, taking responsibility for the integrity of the work as a whole; All authors contributed to and revised the final manuscript.

\section{Funding}

This work was supported by the National Nature Science Foundation of China (No. 81770244), Medical Science and Technology Youth Cultivation Plan (Nos. 17QNP013 and 20QNPY038), Naval Military University Foreign Student Teaching Research and Reform Project (No. WJYA2018005), and Shanghai Municipal Commission of Science and Technology (No. 17ZR1439100).

\section{Availability of data and materials}

The datasets generated and/ or analyzed during the current study are available from the corresponding author upon reasonable request.

\section{Ethics approval and consent to participate}


The authors are accountable for all aspects of the work in ensuring that questions related to the accuracy or integrity of any part of the work are appropriately investigated and resolved. This study utilized the anonymous data available in the elCU database with pre-existing institutional review board approval.

\section{Consent for publication}

Not applicable.

\section{Competing interests}

The authors have no conflicts of interest to disclose.

\section{References}

1. Yancy CW, Jessup M, Bozkurt B, Butler J, Casey DE Jr, Colvin MM, et al. 2017 ACC/AHA/HFSA focused update of the 2013 ACCF/AHA Guideline for the management of heart failure: a report of the American College of Cardiology/American Heart Association Task Force on Clinical Practice Guidelines and the Heart Failure Society of America. J Am Coll Cardiol. 2017;70:776-803.

2. Ponikowski P, Voors AA, Anker SD, Bueno H, Cleland JGF, Coats AJS, et al. 2016 ESC Guidelines for the diagnosis and treatment of acute and chronic heart failure: The Task Force for the diagnosis and treatment of acute and chronic heart failure of the European Society of Cardiology (ESC) Developed with the special contribution of the Heart Failure Association (HFA) of the ESC. Eur Heart J. 2016;37:2129-200.

3. Gheorghiade M, Filippatos G, De Luca L, Burnett J. Congestion in acute heart failure syndromes: an essential target of evaluation and treatment. Am J Med. 2006;119:S3-10.

4. Ezekowitz JA, Hernandez AF, O'Connor CM, Starling RC, Proulx G, Weiss MH, et al. Assessment of dyspnea in acute decompensated heart failure: insights from ASCEND-HF (Acute Study of Clinical Effectiveness of Nesiritide in Decompensated Heart Failure) on the contributions of peak expiratory flow. J Am Coll Cardiol. 2012;59:1441-8.

5. Mebazaa A, Pang PS, Tavares M, Collins SP, Storrow AB, Laribi S, et al. The impact of early standard therapy on dyspnoea in patients with acute heart failure: the URGENT-dyspnoea study. Eur Heart J. 2010;31:832-41.

6. Sepehrvand N, Ezekowitz JA. Oxygen therapy in patients with acute heart failure: friend or foe? JACC Heart Fail. 2016;4:783-90.

7. Moradkhan R, Sinoway LI. Revisiting the role of oxygen therapy in cardiac patients. J Am Coll Cardiol. 2010;56:1013-6.

8. Shuvy M, Atar D, Gabriel Steg P, Halvorsen S, Jolly S, Yusuf S, et al. Oxygen therapy in acute coronary syndrome: are the benefits worth the risk? Eur Heart J. 2013;34:1630-5.

9. Kang MG, Kim K, Ju S, Park HW, Lee SJ, Koh JS, et al. Clinical efficacy of high-flow oxygen therapy through nasal cannula in patients with acute heart failure. J Thorac Dis. 2019;11:410-7. 
10. James SK, Erlinge D, Herlitz J, Alfredsson J, Koul S, Fröbert O, et al. Effect of oxygen therapy on cardiovascular outcomes in relation to baseline oxygen saturation. JACC Cardiovasc Interv. 2020;13:502-13.

11. Jernberg T, Lindahl B, Alfredsson J, Berglund E, Bergström O, Engström A, et al. Long-term effects of oxygen therapy on death or hospitalization for heart failure in patients with suspected acute myocardial infarction. Circulation. 2018;138:2754-62.

12. Hofmann R, James SK, Jernberg T, Lindahl B, Erlinge D, Witt N, et al. Oxygen therapy in suspected acute myocardial infarction. N Engl J Med. 2017;377:1240-9.

13. Stub D, Smith K, Bernard S, Nehme Z, Stephenson M, Bray JE, et al. Air versus oxygen in ST-SegmentElevation myocardial infarction. Circulation. 2015;131:2143-50.

14. Khoshnood A, Carlsson M, Akbarzadeh M, Bhiladvala P, Roijer A, Bodetoft S, et al. The effects of oxygen therapy on myocardial salvage in ST elevation myocardial infarction treated with acute percutaneous coronary intervention: the supplemental oxygen in catheterized coronary emergency reperfusion (SOCCER) study. Cardiology. 2015;132:16-21.

15. Ranchord AM, Argyle R, Beynon R, Perrin K, Sharma V, Weatherall M, et al. High-concentration versus titrated oxygen therapy in ST-elevation myocardial infarction: A pilot randomized controlled trial. Am Heart J. 2012;163:168-75.

16. Dworzynski K, Roberts E, Ludman A, Mant J. Diagnosing and managing acute heart failure in adults: summary of NICE guidance. BMJ. 2014;349:g5695.

17. Metra M, Teerlink JR. Heart failure. Lancet. 2017;390:1981-95.

18. Yancy CW, Jessup M, Bozkurt B, Butler J, Jr CD, Colvin MM, et al. 2017 ACC/AHA/HFSA Focused Update of the 2013 ACCF/AHA Guideline for the Management of Heart Failure: A Report of the American College of Cardiology/American Heart Association Task Force on Clinical Practice Guidelines and the Heart Failure Society of American. J Am Coll Cardiol. 2016;68:1476-88.

19. Park JH, Balmain S, Berry C, Morton JJ, McMurray JJ. Potentially detrimental cardiovascular effects of oxygen in patients with chronic left ventricular systolic dysfunction. Heart. 2010;96:533-8.

20. Rawles JM, Kenmure AC. Controlled trial of oxygen in uncomplicated myocardial infarction. Br Med J. 1976;1:1121-3.

21. Siemieniuk RAC, Chu DK, Kim LH, Güell-Rous MR, Alhazzani W, Soccal PM, et al. Oxygen therapy for acutely ill medical patients: a clinical practice guideline. BMJ. 2018;363:k4169.

22. Bateman RM, Sharpe MD, Jagger JE, Ellis CG, Solé-Violán J, López-Rodríguez M, et al. 36th International Symposium on Intensive Care and Emergency Medicine : Brussels, Belgium. 15-18 March 2016. Crit Care. 2016;20:347.

23. Pollard TJ, Johnson AEW, Raffa JD, Celi LA, Mark RG, Badawi O. The elCU Collaborative Research Database, a freely available multi-center database for critical care research. Sci Data. 2018;5:180178.

24. von Elm E, Altman DG, Egger M, Pocock SJ, Gøtzsche PC, Vandenbroucke JP. The Strengthening the Reporting of Observational Studies in Epidemiology (STROBE) statement: guidelines for reporting 
observational studies. Lancet. 2007;370:1453-7.

25. White IR, Royston P, Wood AM. Multiple imputation using chained equations: Issues and guidance for practice. Stat Med. 2011;30:377-99.

26. Zhang Z. Multiple imputation for time series data with Amelia package. Ann Transl Med. 2016;4:56.

27. Ezekowitz JA, O'Meara E, McDonald MA, Abrams H, Chan M, Ducharme A, et al. 2017 Comprehensive Update of the Canadian Cardiovascular Society Guidelines for the Management of Heart Failure. Can J Cardiol. 2017;33:1342-433.

28. Wang CC, Wu CK, Tsai ML, Lee CM, Huang WC, Chou HH, et al. 2019 Focused Update of the Guidelines of the Taiwan Society of Cardiology for the Diagnosis and Treatment of Heart Failure. Acta Cardiol Sin. 2019;35:244-83.

29. Hu X, Cheng S, Yin Y, Ning L, Xiang L, Zhou Y. The Role of Oxygen Therapy in Normoxemic Acute Coronary Syndrome: A Systematic Review of Randomized Controlled Trials. J Cardiovasc Nurs. 2018;33:559-67.

30. Sepehrvand N, James SK, Stub D, Khoshnood A, Ezekowitz JA, Hofmann R. Effects of supplemental oxygen therapy in patients with suspected acute myocardial infarction: a meta-analysis of randomised clinical trials. Heart. 2018;104:1691-8.

31. Khan AR, Abdulhak AB, Luni FK, Farid TA, Riaz H, Ruzieh M, et al. Oxygen administration does not influence the prognosis of acute myocardial infarction: a meta-analysis. Am J Ther. 2019;26:e15160.

32. Abuzaid A, Fabrizio C, Felpel K, Al Ashry HS, Ranjan P, Elbadawi A, et al. Oxygen therapy in patients with acute myocardial infarction: a systemic review and meta-analysis. Am J Med. 2018;131:693701.

33. Hofmann R, Witt N, Lagerqvist B, Jernberg T, Lindahl B, Erlinge D, et al. Oxygen therapy in STelevation myocardial infarction. Eur Heart J. 2018;39:2730-9.

34. Pountain SJ, Roffe C. Does routine oxygen supplementation in patients with acute stroke improve outcome? BMJ. 2012;345:e6976.

35. Saugstad OD. Resuscitation of newborn infants: from oxygen to room air. Lancet. 2010;376:1970-1.

36. Lukkarinen HP, Laine J, Kääpä PO. Lung epithelial cells undergo apoptosis in neonatal respiratory distress syndrome. Pediatr Res. 2003;53:254-9.

37. McNulty PH, Robertson BJ, Tulli MA, Hess J, Harach LA, Scott S, et al. Effect of hyperoxia and vitamin $\mathrm{C}$ on coronary blood flow in patients with ischemic heart disease. J Appl Physiol. 2007;102:2040-5.

38. O' Halloran M, O'Donoghue E, Dainty C. Measurement of the Retinal Arteriolar Response to a Hyperoxic Provocation. J Biomed Opt. 2014;19:076012.

39. Tajima Y, Takuwa H, Nishino A, Matsuura T, Kawaguchi H, Ikoma Y, et al. Cerebral hemodynamic response to acute hyperoxia in awake mice. Brain Res. 2014;1557:155-63. 
40. Helmerhorst HJ, Schultz MJ, van der Voort PH, de Jonge E, van Westerloo DJ. Bench-to-bedside review: the effects of hyperoxia during critical illness. Crit Care. 2015;19:284.

41. Jezek P, Hlavatá L. Mitochondria in homeostasis of reactive oxygen species in cell, tissues, and organism. Int J Biochem Cell Biol. 2005;37:2478-503.

42. Mak S, Egri Z, Tanna G, Colman R, Newton GE. Vitamin C prevents hyperoxia-mediated vasoconstriction and impairment of endothelium-dependent vasodilation. Am J Physiol Heart Circ Physiol. 2002;282:H2414-21.

43. Zhilyaev SY, Moskvin AN, Platonova TF, Gutsaeva DR, Churilina IV, Demchenko IT. Hyperoxic vasoconstriction in the brain is mediated by inactivation of nitric oxide by superoxide anions. Neurosci Behav Physiol. 2003;33:783-7.

44. Ruggiu M, Aissaoui N, Nael J, Haw-Berlemont C, Herrmann B, Augy JL, et al. Hyperoxia effects on intensive care unit mortality: a retrospective pragmatic cohort study. Crit Care. 2018;22:218.

45. Mak S, Azevedo ER, Liu PP, Newton GE. Effect of hyperoxia on left ventricular function and filling pressures in patients with and without congestive heart failure. Chest. 2001;120:467-73.

46. Smit B, Smulders YM, van der Wouden JC, Oudemans-van Straaten HM, Spoelstra-de Man AME. Hemodynamic effects of acute hyperoxia: systematic review and meta-analysis. Crit Care. 2018;22:45.

47. Haque WA, Boehmer J, Clemson BS, Leuenberger UA, Silber DH, Sinoway LI. Hemodynamic effects of supplemental oxygen administration in congestive heart failure. J Am Coll Cardiol. 1996:27:353-7.

48. Nael J, Ruggiu M, Bailleul C, Ortuno S, Diehl JL, Vimpère D, et al. Impact of hyperoxia on patients hospitalized in an intensive care unit for acute heart failure. Arch Cardiovasc Dis. 2019;112:748-53.

49. Durlinger EMJ, Spoelstra-de Man AME, Smit B, de Grooth HJ, Girbes ARJ, Oudemans-van Straaten $\mathrm{HM}$, et al. Hyperoxia: at what level of SpO2 is a patient safe? a study in mechanically ventilated ICU patients. J Crit Care. 2017;39:199-204.

50. Chu DK, Kim LH, Young PJ, Zamiri N, Almenawer SA, Jaeschke R, et al. Mortality and morbidity in acutely ill adults treated with liberal versus conservative oxygen therapy (IOTA): a systematic review and meta-analysis. Lancet. 2018;391:1693-705.

51. Beasley R, Chien J, Douglas J, Eastlake L, Farah C, King G et al: Thoracic Society of Australia and New Zealand oxygen guidelines for acute oxygen use in adults: 'Swimming between the flags'. Respirology. 2015;20:1182-91.

52. O'Driscoll BR, Howard LS, Earis J, Mak V. BTS guideline for oxygen use in adults in healthcare and emergency settings. Thorax. 2017;72:ii1-90.

53. Sepehrvand N, Alemayehu W, Rowe BH, McAlister FA, van Diepen S, Stickland M, et al. High vs. low oxygen therapy in patients with acute heart failure: HiLo-HF pilot trial. ESC Heart Fail. 2019;6:667-77.

\section{Figures}




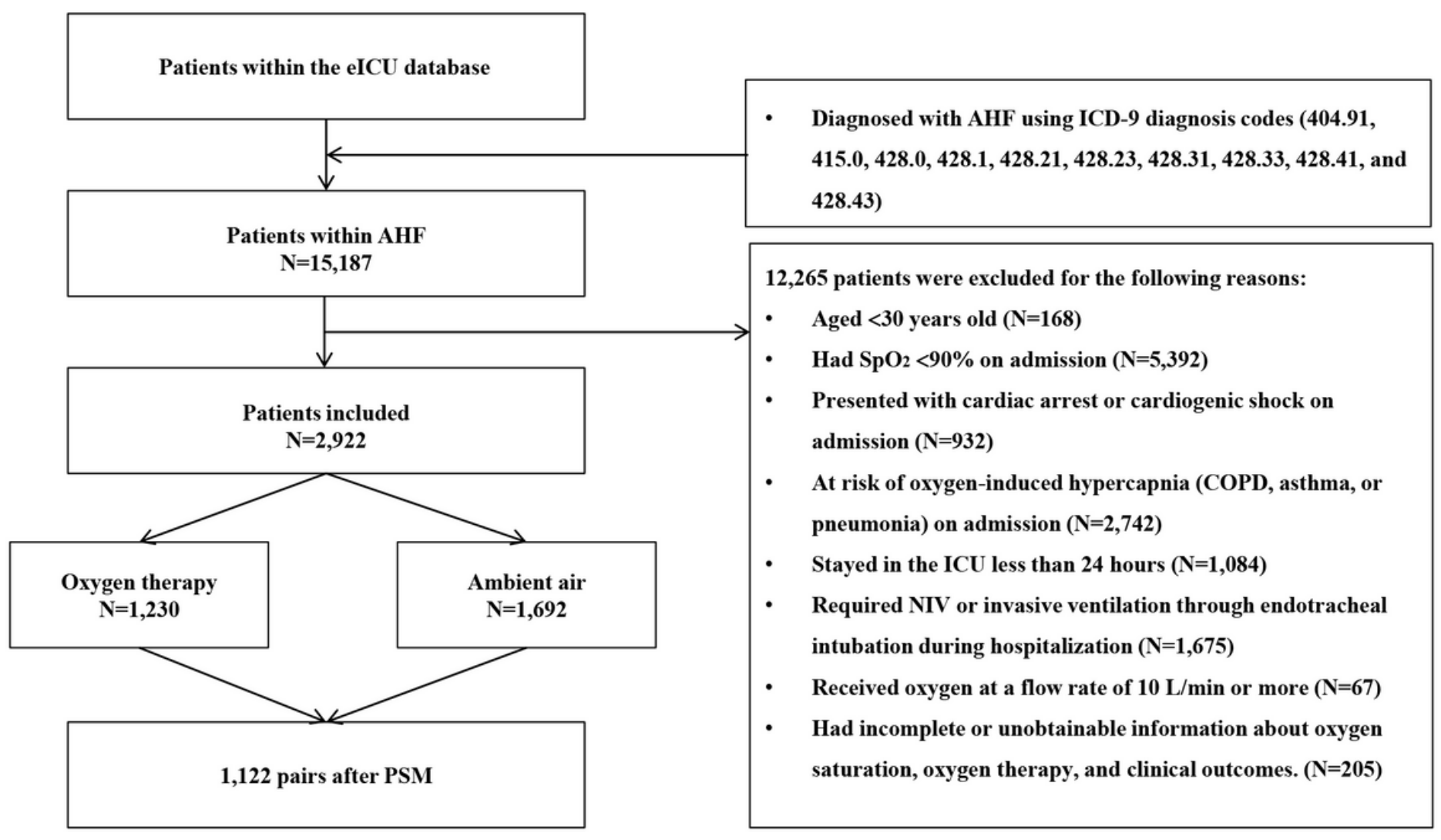

\section{Figure 1}

Case inclusion flowchart. Abbreviations: elCU: Electronic Intensive Care Unit; AHF: Acute heart failure; PSM: Propensity score matching; ICD-9: International Classification of Diseases, Ninth Revision; Sp02: Pulse oximetry-derived oxygen saturation; COPD: Chronic obstructive pulmonary disease; NIV: noninvasive ventilation. 


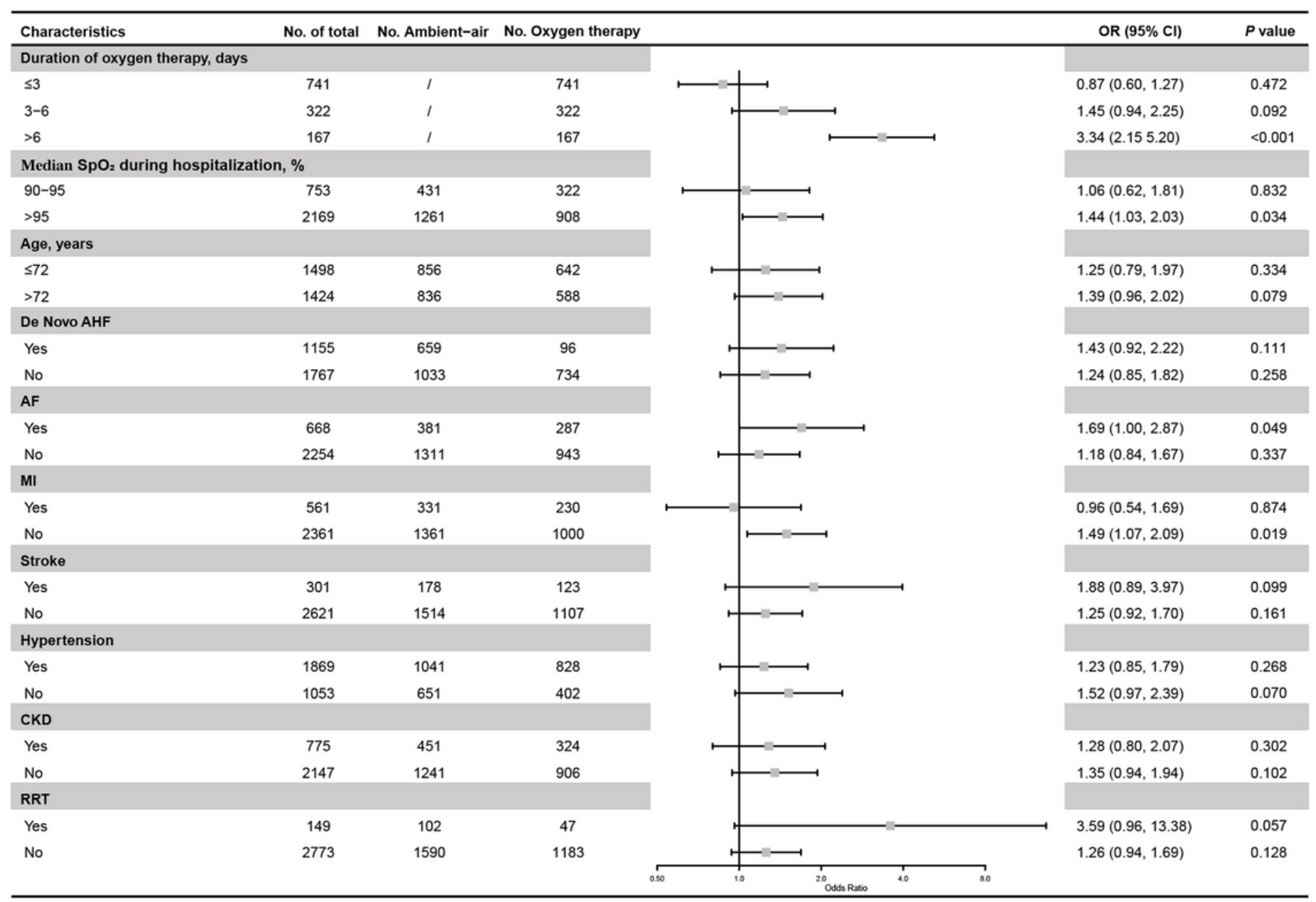

Figure 2

The association between oxygen therapy and all-cause in-hospital mortality in subgroup analysis. Abbreviations: OR: Odds ratio; Cl: Confidence interval; Sp02: Pulse oximetry-derived oxygen saturation; BMI: Body mass index; AF: Atrial fibrillation; MI: Myocardial infarction; CKD: Chronic kidney disease; RRT: Renal replacement treatment.

\section{Supplementary Files}

This is a list of supplementary files associated with this preprint. Click to download.

- AdditionalfileTableS15.docx 